\title{
The HURT (Headache Under-Response to Treatment) questionnaire: utility in a specialist care center in Denmark
}

\author{
ML Westergaard', RH Jensen², TJ Steiner ${ }^{3^{*}}$ \\ From The European Headache and Migraine Trust International Congress \\ London, UK. 20-23 September 2012
}

\section{Background}

The HURT Questionnaire was developed by Lifting The Burden, a non-governmental organization working in official relations with the World Health Organization, as a tool to aid in the management of headache. It has eight questions which the patient answers as a measure of effectiveness of intervention, by indicating when outcome is less than optimal, and by suggesting what changes in management might lead to improvement.

\section{Objective}

The objectives of the study were a) to assess test-retest reliability of HURT and b) to show responsiveness to treatment-induced change.

\section{Methods}

The questionnaire was administered on three occasions in a specialist headache center: pre-visit, at first visit, and when the specialist judged that the best possible outcome had been achieved.

\section{Results}

Of 143 patients, 114 completed all questionnaires and records of 110 were available for analysis. They were mostly female (2:1), with mean age 44.4 years and headache duration of 15.6 years. Internal consistency reliability was a $=0.79$ to 0.90 . Test-retest reliability varied widely: highest for the question on number of days of headache per month $\left(r_{s}=0.84, k a p p a=0.68\right)$ and lowest on delaying medication because of side effects $\left(r_{s}=0.33\right.$, kappa $\left.=0.27\right)$. Responses post-intervention compared with baseline indicated a favourable outcome overall ( $80 \%$ of patients),

${ }^{3}$ Norwegian University of Science and Technology, Norway

Full list of author information is available at the end of the article reflecting specialist assessment that the best possible outcome had been achieved. There was no improvement in concerns about side-effects of medication ( $\mathrm{p}=0.28)$. There was a significant association between improvement in HURT total score and migraine diagnosis $(\mathrm{p}=0.04)$. Patients with migraine showed the biggest changes in total scores. Records of non-responders were reviewed and there were no significant differences in terms of age $(\mathrm{p}=0.28)$ and gender $(\mathrm{p}=0.15)$, although 12 patients who were discharged after the study period were followed-up for a significantly longer time $(\mathrm{p}<0.001)$.

\section{Conclusions}

The questionnaire can help patients describe headache symptoms, disability, medication use, self-efficacy, and knowledge about headache. It has utility in a specialist care setting but must be tested in primary care, for which it was originally designed.

\section{Acknowledgements}

The authors acknowledge the work of clinicians and researchers of Lifting The Burden in conceptualizing this paper and developing the HURT questionnaire.

\section{Author details}

'Danish Headache Center, Denmark. ${ }^{2}$ Imperial College London, UK. ${ }^{3}$ Norwegian University of Science and Technology, Norway.

Published: 21 February 2013

References

1. Steiner TJ: Lifting The burden: the global campaign against headache. Lancet Neurol 2004, 3:204-5.

2. Buse DC, Sollars CM, Steiner TJ, et al: Why HURT? A review of clinical instruments for headache management. Curr Pain Headache Rep 2012, 16(3):237-54.

3. Lifting The Burden: HURT Index Questionnaire (v 2.2). [http://www.l-t-b. org/assets/96/AB9C64EE-D800-01AB-1FAC446E25B0DF88_document/ HURT_NY_revision.pdf], (undated, accessed 31 May 2012). 
doi:10.1186/1129-2377-14-S1-P97

Cite this article as: Westergaard et al: The HURT (Headache Under-

Response to Treatment) questionnaire: utility in a specialist care center in Denmark. The Journal of Headache and Pain 2013 14(Suppl 1):P97.

\section{Submit your manuscript to a SpringerOpen ${ }^{\mathcal{O}}$ journal and benefit from:}

- Convenient online submission

- Rigorous peer review

- Immediate publication on acceptance

- Open access: articles freely available online

- High visibility within the field

- Retaining the copyright to your article

Submit your next manuscript at $\gg$ springeropen.com 